\title{
Dorsal Midbrain Syndrome in Multiple Sclerosis with Magnetic Resonance Imaging Correlation
}

\author{
A. Costantino, S.E. Black, T. Carr, R.L. Nicholson and J.H. Noseworthy
}

\begin{abstract}
We describe the clinical characteristics and a series of magnetic resonance imaging (MRI) studies in a patient with the features of dorsal midbrain syndrome occurring in the setting of multiple sclerosis. A T2-weighted MRI study revealed a discrete abnormality in the tectum of the midbrain whereas a high volume delayed computed tomography (CT) scan was uninformative. In parallel with remission of the clinical findings, the MRI abnormality diminished over time and was no longer visible at one year suggesting that some MRI detected MS lesions can completely disappear with time. This report demonstrates the use of MRI to detect and to follow sequentially sites of known disease activity in MS.
\end{abstract}

\begin{abstract}
RÉSUMÉ: Les syndrome mésencéphalique dorsal dans la sclérose en plaques et ses corrélations avec les données obtenues par résonance magnétique Nous décrivons les caractéristiques cliniques et une série d'images obtenues par résonance magnétique (RM) chez un patient présentant un syndrome mésencéphalique dorsal dans le contexte d'une sclérose en plaques (SEP). Une étude du RM-T2 révéla une anomalie discrète dans le toit du mésencéphale alors qu'une tomodensitométrie à haut volume était négative. Cette image au RM diminua avec le temps, parallèlement à l'évolution clinique et disparut complètement après un an. Le présent rapport indique donc l'utilité du RM pour détecter et suivre les lésions dans la SEP.
\end{abstract}

Can. J. Neurol. Sci. 1986; 13:62-65

The dorsal midbrain syndrome (DMS) also called Parinaud's, ${ }^{1}$ Koeber-Salus-Elschnig, ${ }^{2}$ and the Sylvian Aqueduct Syndrome, ${ }^{3}$ consists of impaired vertical gaze, retraction nystagmus, pupillary abnormalities, convergence nystagmus, convergence spasm, vertical nystagmus and extra-ocular palsies. ${ }^{2}$ The first three signs are most commonly present; the constellation seen in a particular patient may reflect the extent of disease. ${ }^{3}$ Pineal gland tumours and midbrain infarction are the most common etiologies, but multiple sclerosis (MS) can be a rare cause of the DMS. ${ }^{4.5}$

We present a patient with the DMS as an isolated manifestation of clinically definite multiple sclerosis (CDMS), who demonstrated an appropriate lesion on magnetic resonance imaging (MRI) in the acute phase and resolution of both the clinical syndrome and MRI abnormality at subsequent follow-up.

\section{Case Report}

A 45-year-old right-handed housewife experienced sudden total loss of vision in her right eye at age 29 (1967). This recovered within one month but she then lost vision in her left eye. Her vision gradually returned to normal over the next month. She remained well until November, 1983 when she experienced an acute onset of vertical diplopia accompanied by postural vertigo and nausea. This persisted for one week after which her dizziness and diplopia improved and could only be precipitated by upward gaze.

Examination at this time revealed optic atrophy of the right eye with a corrected visual acuity of 20/30. Visual acuity was normal in the left eye. On attempted upward gaze she had upgaze paralysis, vertical nystagmus, convergence spasm, and convergence-retraction nystagmus affecting both eyes. Bell's phenomenon could not be elicited but the oculovestibular response was present. No pupillary or other extraocular movement abnormalities were detected and the remainder of her neurological examination was normal.

This paper was presented in part at the Nineteenth Canadian Congress of Neurological Sciences in Edmonton, Alberta, June 1984

From the Department of Clinical Neurological Sciences (Drs. Costantino, Black, Noseworthy) and the Department of Nuclear Medicine, St. Joseph's Hospital, University of Western Ontario (Drs. Carr and Nicholson)

Received May 30, 1985. Accepted in revised form September 24, 1985

Reprint requests to: Dr. J.H. Noseworthy, Department of Clinical Neurological Sciences, University Hospital, P.O. Box 5339, Postal Stn. A, London, Ontario, Canada N6A 5A5 
CSF examination revealed normal glucose and protein with 17 white blood cells/per $\mathrm{mm}^{3}$ ( $100 \%$ mononuclear cells). Oligoclonal banding was present in the CSF and absent in serum. Brain stem auditory evoked responses and somatosensory evoked potentials were normal but the pattern visual evoked responses (PVER) of the right eye were prolonged to $116 \mathrm{msec}$ (normal $<106 \mathrm{msec}$ ). ${ }^{6.7} \mathrm{High}$ volume delayed computerized tomography ${ }^{8,9}$ (GE8800) prior to steroid treatment revealed no definite lesions.

The patient was treated for 10 days with $60 \mathrm{mg}$ of delta-cortisone and this was then tapered over several weeks. She made a gradual recovery over the next three months. When seen nine months later she complained of diplopia on upward gaze only when very fatigued and exhibited a few beats of nystagmus on upward gaze. This had resolved by one year and no residual signs of the DMS could be clinically detected at that time.

\section{Magnetic Resonance Imaging (MRI)}

MRI was performed on a prototype $0.15 \mathrm{~T}$ resistive magnet (Technicare Inc., Solon $\mathrm{OH}$ ) which acquired data using a $256 \times$ 128 matrix (pixel size of $1.1 \times 2.2 \mathrm{~mm}$ ) displayed as a $256 \times 256$ image. In the MRI examination immediately prior to steroid therapy, within a few days of her CT scan, and subsequently at three months, single sagittal slices $(1.5 \mathrm{~cm}$ full width half maximum) were obtained near the midline by both spin echo $(\mathrm{SE})(\mathrm{TE}=60 \mathrm{msec}, \mathrm{TR}=1000 \mathrm{msec})$ and inversion recovery (IR) techniques $(\mathrm{TI}=450, \mathrm{TE}=30, \mathrm{TR}=1500)$. The brain was also surveyed using an anisotropic $\mathrm{SE}$ (TE $=60$, TR = 1000 ) collection of 32 transverse slices ( $1.7 \mathrm{~cm}$ thick FWHM) and two $\mathrm{SE}$ single slices at the upper ventricular levels (TE = 120 , TR $=1000$ ). The patient was re-examined one year later with a multiple slice, multiecho technique that produced 151.0 $\mathrm{cm}$ thick transverse slices $(\mathrm{TE}=60,120, \mathrm{TR}=2040)$ and two series of $0.75 \mathrm{~cm}$ sagittal slices (15 sagittal slices at $\mathrm{TE}=60$, $120, \mathrm{TR}=2040 ; 5$ slices at $\mathrm{TE}=60,120, \mathrm{TR}=1000)$. Five IR sagittal slices were also obtained near the midline (TI $=400$, $\mathrm{TE}=30$, $\mathrm{TR}=1600$ ).

The initial scan showed a small area of increased signal intensity compatible with an MS plaque in the dorsal midbrain on the midsagittal spin echo slice (Figure 1). A small area of increased signal was also seen in the left periatrial region on an axial spin echo slice $(\mathrm{TE}=60, \mathrm{TR}=1000)$ in the transverse plane. In parallel with her clinical improvement a follow-up scan at three months showed diminution of the tectal lesion, but it could still be discerned. This lesion was no longer visible at one year in spite of improved image quality and a survey which included more slices and the application of additional echo delays and repetition rates that have been reported to be sensitive in the detection of MS lesions ${ }^{10,11,12}$ (Figure 2a). In the axial spin echo images focal areas of increased signal were detected in the periventricular and supraventricular regions (Figure 2b). These lesions were typical for MS and were clinically asymptomatic. Some of them may have been new, although improved image quality and increased sensitivity in the later series made comparison with the earlier scans difficult.

\section{Discussion}

This patient meets the criteria for clinically definite multiple sclerosis (CDMS) recently outlined by Poser et al. ${ }^{13}$ Optic nerve involvement was confirmed by optic atrophy and an abnormal PVER. The presence of oligoclonal bands in the CSF provided laboratory confirmation of the diagnosis. ${ }^{14}$

The Dorsal Midbrain Syndrome was first comprehensively defined in 1946 by Kestenbaum ${ }^{2}$ and included the following

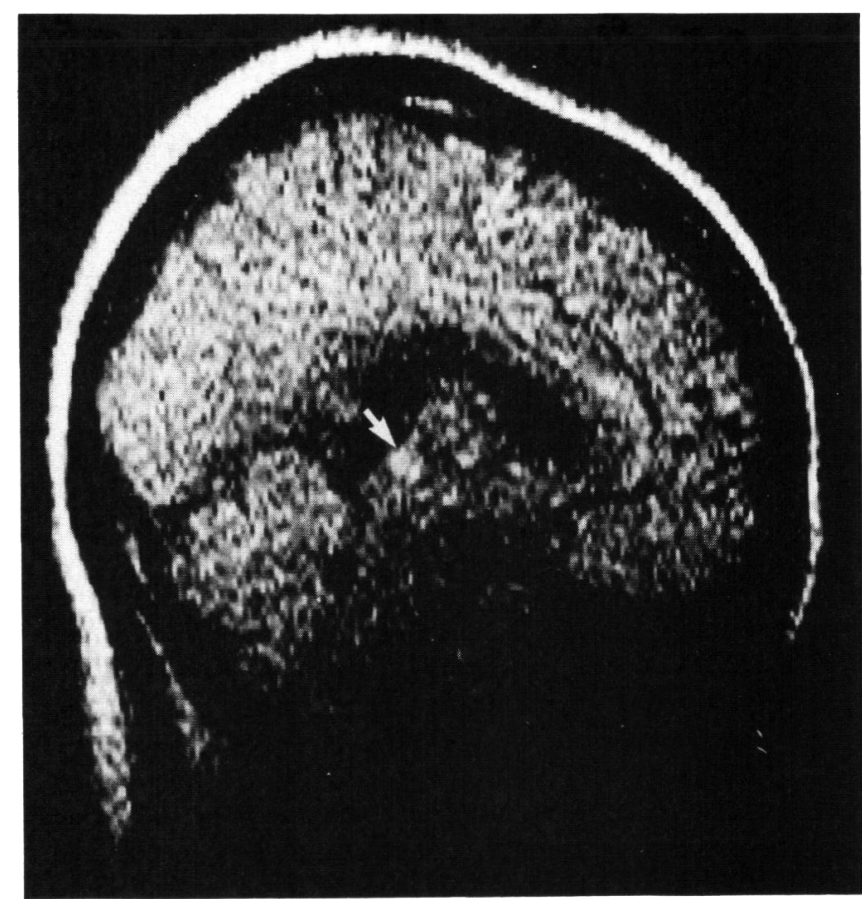

Figure 1-Midsagittal MRI using a single slice spin echo(SE) technique (TE $=60, T R=1000) 2$ weeks after the acute onset of the dorsal midbrain syndrome. A discrete round area of increased signal intensity (prolonged T2) can be seen in the dorsal midbrain (arrow). An inversion-recovery (IR) image (not shown) of the same slice showed signal void in the same location but this could not be reliably distinguished from the low signal of the adjacent quadrigeminal cistern.

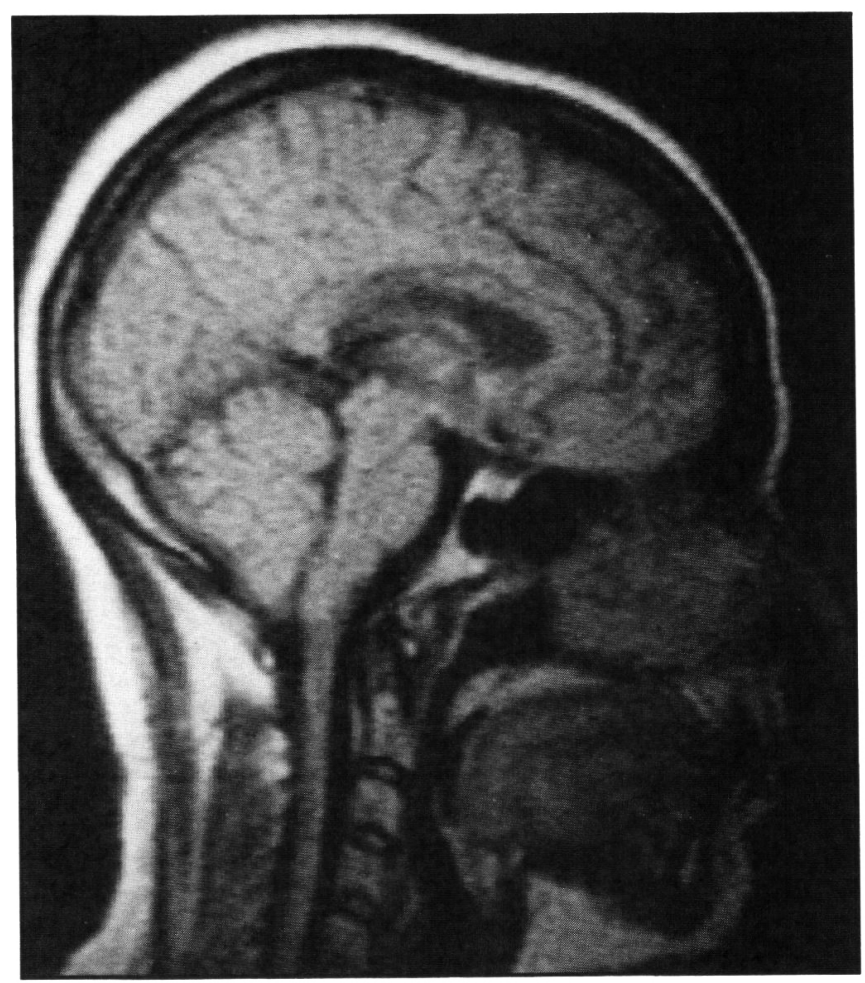

Figure $2 a-M i d s a g i t t a l$ slicesobtained one year later by a multislice multiecho $S E$ technique. The dorsal midbrain lesion could no longer be seen despite the obvious improved image quality using the same pulse sequence (TE = $60 . T R=1000$ ) as a year earlier. Images (not shown) using a longer repetition rate $(T R=2000)$ and longer echoes $(T E=120, T R=1000$ and 2000) likewise did not reveal any brainstem lesions. 


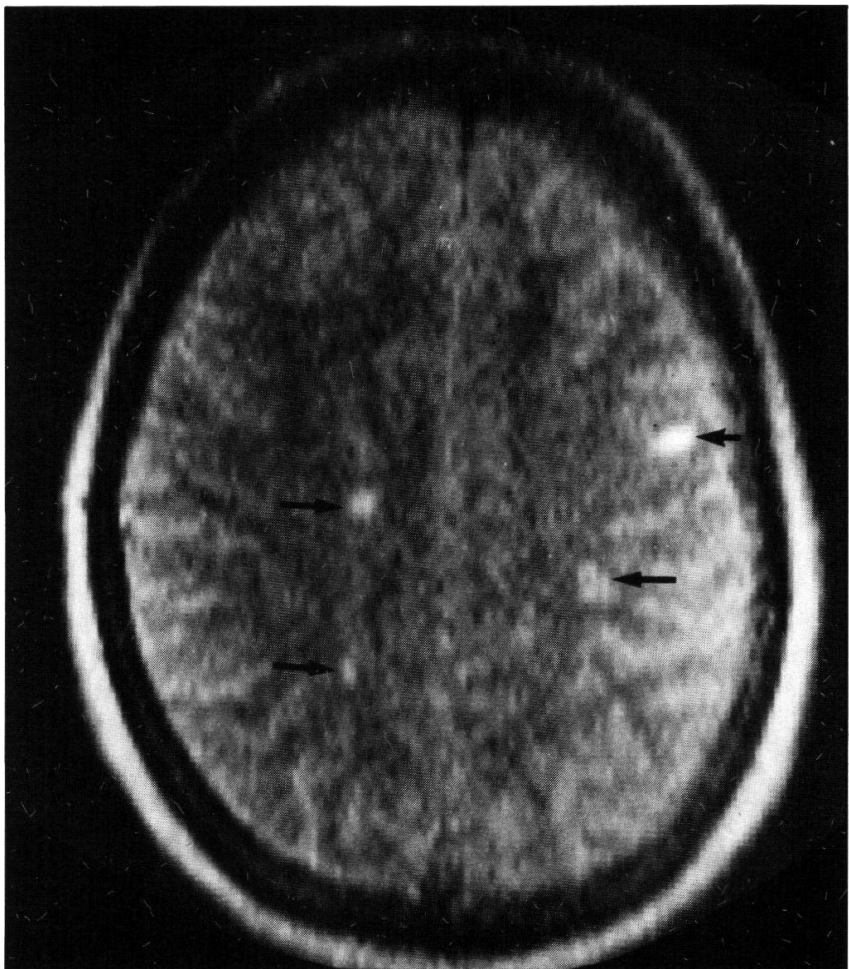

Figure $2 b-$ Transverse supraventricular MR image obtained bythe multislice multiecho $S E$ technique $(T E=60,120 ; T R=2040)$ at one year revealed four foci of increased signal intensity in the white matter (arrows). These changes are consistent with the diagnosis of multiple sclerosis.

signs: (1) impaired vertical gaze, (2) retraction nystagmus, (3) pupillary abnormalities, (4) convergence spasm, (5) convergence nystagmus, (6) vertical nystagmus, and (7) extra-ocular palsies. Five of the seven criteria $(1,2,4,5$ and 6$)$ could be elicited in our patient in the acute phase of her exacerbation.

The control of vertical eye movements is thought to be located in the dorsal midbrain in the region of the posterior commissure and mesencephalic tegmentum. ${ }^{15,16,17}$ Convergence and retraction nystagmus, described respectively as intermittent quick jerking movements of the eyes toward each other and retraction of the globes, are believed to be closely related. ${ }^{18,19}$ The mechanism of convergence-retraction nystagmus is not clear, but it may represent a release phenomenon of the supranuclear cortical inhibitory fibres which results in a loss of the normal pattern of reciprocal innervation and an anomalous co-firing of the rectus muscles. ${ }^{20}$ Upgaze paralysis and convergence-retraction nystagmus are both associated with lesions of the dorsal midbrain and, therefore, often occur together clinically.

It is quickly becoming established that MRI is the most sensitive neuroimaging technique for the detection of MS plaques, not only in the posterior fossa but also in the cerebral hemispheres. ${ }^{10.12 .21-26}$ Although there are few studies published to date comparing MRI to high volume delayed CT scanning, it appears that MRI is the more sensitive imaging modality in patients with MS. ${ }^{25.26}$ Typically the lesions of MS have longer $\mathrm{T} 1$ and $\mathrm{T} 2$ relaxation times than normal white matter and, therefore, appear as areas of decreased signal intensity on $\mathrm{T} 1$ weighted images and of increased signal intensity on $\mathrm{T} 2$ weighted images. ${ }^{10,21,24,25,27}$ Recent studies have suggested that the spin echo technique, using echo delays of 60-120 msec and repetition times greater than $1000 \mathrm{msec}$, is the most sensitive pulse sequence in detecting MS lesions, ${ }^{10,11,12,28}$ although earlier studies reported greater sensitivity with inversion-recovery pulse sequences (IR). ${ }^{24,25}$ One group has reported that SE $(120 / 1000)$ was the most useful screening procedure, although IR may be more revealing in the brainstem and a repetition time around $2000 \mathrm{msec}$ may provide more contrast in lesions of the white matter remote from the ventricular system. ${ }^{10}$

It remains to be clarified how these MRI abnormalities relate to the age of the plaques and the pathological changes within them. It is known that contrast enhancement on CT correlates with sites of active inflammation and demyelination in MS. ${ }^{29}$ Failure of the high volume delayed CT study to identify an abnormality in our patient does not permit us to infer that the blood-brain barrier was intact at the site of the midbrain lesion as the lack of enhancement may have been due to the known insensitivity of CT studies in the posterior fossa. The single autopsy-MRI correlation that has been published reported that areas of demyelination corresponded to areas of increased signal intensity on T2 weighted MRI images. ${ }^{30}$ Preliminary studies designed to correlate the pathological findings in the experimental allergic encephalomyelitis animal model of MS with the changes in MRI relaxation times have suggested that the $\mathrm{T} 1$ and $\mathrm{T} 2$ abnormalities seen with inflammation and demyelination may normalize in the presence of extensive cellular infiltration. ${ }^{31}$ These studies imply that apparent improvement in an MRI image may not always mean resolution of disease activity but rather may reflect changes in the degree of cellular infiltration, tissue protein content or the amount of free water locally in an MS plaque.

There have been few studies of serial magnetic resonance imaging in MS patients, but the limited evidence available suggests that lesions may remain unchanged, may diminish or enlarge and that new lesions can appear. ${ }^{25,26.29}$ Many lesions, especially in the hemispheric periventricular white matter, are clinically asymptomatic and it is not possible to determine whether they represent acute or chronic sites of activity. In lesions of uncertain age quantitative sequential studies have shown unpredictable changes in $\mathrm{T} 1$ and $\mathrm{T} 2$ values. ${ }^{25}$ The actual disappearance of MRI-detected abnormalities has been noted only infrequently and this is felt to be uncommon. ${ }^{29}$ Our patient is of particular interest because she had a discrete lesion in the dorsal midbrain which corresponded to her clinical signs during an acute exacerbation. This suggested that the midbrain MRI lesion represented an active and, presumably, acute MS plaque. She improved substantially and at three months the MRI lesion had correspondingly diminished. By one year she had fully recovered and the lesion was no longer visible on MRI despite technical improvements which allowed a more comprehensive survey with better resolution. This suggests that the alterations in $\mathrm{T} 1$ and $\mathrm{T} 2$ properties (especially $\mathrm{T} 2$ prolongation), which occurred during the acute exacerbation were no longer great enough to cause visible contrast with normal white matter and to permit detection by MRI. In a lesion of this size, accurate T1 and $T 2$ measurement is impossible due to partial volume averaging. At the time of the final MRI study several previously undetected small areas of increased signal were seen in the hemispheric white matter. Because of the intervening technical improvements it cannot be determined if these foci represented new plaques or simply reflected the increased sensitivity of the imaging technique. 


\section{ACKNOWLEDGEMENTS}

The authors wish to thank Drs. A.J. Hudson and A. Fox for their assistance. S.E. Black is grateful to the Ontario Heart and Stroke Foundation for personal support.

\section{REFERENCES}

1. Parinaud H. Paralysie des mouvements associés des yeux. Arch Neurol 1883; 5: 145-154.

2. Kestenbaum A. Clinical methods of neuro-ophthmologic examination. New York: Grune and Stratton, Inc., 1946.

3. Hatcher MA and Klintworth GK. The sylvian aqueduct syndrome. Arch Neurol 1966; 15: 215-222.

4. Segarra JM, Ojeman RJ. Convergence nystagmus. Neurology $1961 ; 11: 883-893$.

5. Slyman JF, Kline LB. Dorsal midbrain syndrome in multiple sclerosis. Neurology 1981; 31: 196-198.

6. Trojaborg W, Petersen E. Visual and somatosensory evoked cortical potentials in multiple sclerosis. J Neurol Neurosurg Psychiat 1979; 42: 323-330.

7. Chiappa KH. Pattern-Shift visual evoked potentials: Interpretation (Chap. 3) in evoked potentials in clinical medicine. New York, New York: Raven Press, 1983: 63-95.

8. Vinuela FV, Fox AJ, Debrun GM, Feasby TE, Ebers GC. New perspectives in computed tomography of multiple sclerosis. AJNR 1982; 3: 277-281.

9. Sears ES, McCammon A, Bigelow R, Hayman LA. Maximizing the harvest of contrast enhancing lesions in MS. Neurology 1982; 32: $815-20$.

10. Lukes SA, Crooks LE, Aminoff MJ et al. Nuclear magnetic resonance imaging in multiple sclerosis. Ann Neurol 1983; 13:592-601.

11. Crooks LE, Hoenninger J, Arakawa $M$ et al. High resolution magnetic resonance imaging. Radiology 1984; 150: 163-171.

12. Runge VM, Price AC, Kirshner HS et al. Magnetic resonance imaging of multiple sclerosis: A study of pulse technique efficacy. AJR 1984; 143: 1015-26.

13. Poser CM, Paty DW, Scheinberg L et al. New diagnostic criteria for multiple sclerosis: guidelines for research protocols. Annals of Neurology 1983; 13: 227-231.

14. Ebers GC, Paty DW. CSF Electrophoresis in one thousand patients. Can J Neurol Sci 1980; 7: 275-280.

15. Buttner-Ennever JA, Buttner U, Cohen B, Baumgartner G. Vertical gaze paralysis and the rostral interstitial nucleus of the medial longitudinal fasciculus. Brain 1982; 105: 125-149.
16. Thames PB, Trobe JD, Ballinger WE. Upgaze paralysis caused by lesion of the periaqueductal gray matter. Arch Neurol 1984; 41 : 437-440.

17. Baloh RW, Furman JM, Yee RD. Dorsal midbrain syndrome: Clinical and oculographic findings. Neurology 1985; 35: 54-60.

18. Christoff N, Anderson PJ, Bender MB. Convergence and retractory nystagmus. Trans Amer Neurol Assoc 1960; 85: 29-32.

19. Barany E. Verein für Psychiatrie \& Neurologie in Wien, Wien Klin Wschr 1913; 26: 480-82.

20. Leigh RJ, Zee OS. The neurology of eye movements. F.A. Davis, USA, 1983.

21. Young IR, Hall AS, Pallis CA, Legg NJ, Bydder GM, Steiner RE. Nuclear magnetic resonance imaging of the brain in multiple sclerosis. Lancet 1981; 4 November 1063-1066.

22. Bydder GM, Steiner RE, Young IR et al. Clinical NMR imaging of the brain: 140 cases. AJNR 1982; 3: 459-480, AJR 1982; 139: 215-236.

23. Brant-Zawadzki M, Davis PL, Crooks LE et al. NMR demonstration of cerebral abnormalities: comparison with CT. AJNR 1983; 4: 117-124, AJR 1983; 140: 847-54.

24. Buonanno FS, Kistler JP, Lehrich JR, Noseworthy JH, New PEJ, Brady TJ. $H$ nuclear magnetic resonance imaging in multiple sclerosis. Neurologic Clinics 1983; Volume 1 (No. 3): 757-762.

25. Noseworthy JH, Buonanno FS, Kistler JP et al. True three-dimensional quantitative nuclear magnetic resonance neuroimaging in multiple sclerosis. Neurology 1984; 34: (Suppl. 1), 135-136.

26. Johnson MA, Li DKB, Bryant DJ, Payne JA. Magnetic resonance imaging: Serial observations in multiple sclerosis. AJNR 1984;5: 495-99.

27. Mills CM, Crooks LE, Kaufman L, Brant-Zawadzki M. Cerebral abnormalities: Use of calculated $\mathrm{T} 1$ and $\mathrm{T} 2$ magnetic resonance images for diagnosis. Radiology 1984; 150: 87-94.

28. Young IR, Randell CP, Kaplan PW, James A, Bydder GM, Steiner RE. Nuclear magnetic resonance (NMR) imaging in white matter of the brain using spin echo sequences. JCAT 1983; 7: 290-94.

29. Noseworthy JH, Paty DW, Ebers GC. Neuroimaging in multiple sclerosis. Neurologic Clinics 1984; Vol. 2 (No. 4): 759-777.

30. Stewart WA, Hall LD, Berry K, Paty DW. Correlation between NMR scan and brain slice data in multiple sclerosis. Lancet 1984; $2: 412$.

31. Karlik SJ, Noseworthy JH, Gilbert J, St. Louis J, Strejan G. Nuclear magnetic resonance (NMR) spectroscopy studies in experimental allergic encephalomyelitis (EAE). Abstracts of the third annual scientific meeting of the society of magnetic resonance in medicine. P. 399-400. August 1984. 